\title{
The first movements of the child the mental structures and dyadic relationship with the mother
}

\author{
Rosa Sgambelluri \\ Pegaso Online University \\ Piazza Trieste e Trento n.48, Napoli, ITALY
}

\begin{abstract}
Mother and child in their act and react, constitute a place in which the child lays the foundations of one of the most developed areas of its competence: reading and interpretation of signals and emotional expressions of other people's behaviour.

Several studies have shown that the child is provided with a social awareness at birth, characterized by a preference for faces, direct gaze and imitation, a true "preadaptation" which enables to social relationship and emerging both within the ability of expression and organization behavior and in the perceptual ability.
\end{abstract}

Keywords: movement, dyadic relationship, mind, intelligence, learning, education

\section{INTRODUCTION}

Right from intrauterine life, through movement, gestures and physical contact children build a first image of themselves in relation to others and begin to discover the world.

The recognition of connections between the different dimensions of development has reinforced the view of man as a psychophysical mind-body unity and redefined the importance of movement as a fundamental learning tool for the education of the child as a person.

Some of the theories involving the role of movement in infant development that provide important contributions in the broadest sense of the term are Piaget's theory, Vygotsky's cultural-historical theory and Bowlby's attachment theory.

Jean Piaget's studies on Genetic Epistemology, which began in 1936, examined the development of intelligence in children from birth to adolescence. True to the spirit of Rousseau and Darwin, the Geneva-born scholar describes the evolutionary path of a person as a long and complex process. He did not agree with the nativist and behaviourist theories of learning and proposed an organicist theory recognising continuity between biological organisation and intelligence.

Piaget believes in continuity between intelligence and the purely biological processes of morphogenesis and adaptation to the environment, rather than intelligence itself is a form of adaptation. The body adapts by building new material forms to insert into those of the universe, while intelligence expands this creation by building mental structures that can be applied to those of the environment"(Piaget, 1973).

In the study of intelligence, Piaget identified functional aspects and structural aspects: the first describe how our mind works in its activity of knowledge and how it changes during development, while the structural aspects are so-called cognitive structures, namely the result of the functioning of our mind. Piaget sees mental and physical development as an effect of the 
interaction between the subject and the physical and social environment. Child cognitive development occurs by selfgeneration starting from a biological foundation in the dialectic between two processes: assimilation and accommodation.

Assimilation is the process through which data from the outside is incorporated into the mental and physical schemes of the child without changing them, whereas accommodation takes over when the assimilation process is unable to cope with the changes coming from the environment, which therefore modify the child's old schemes to adapt them to the external data.

Assimilation and accommodation are not mutually exclusive, but complement one another to obtain balance between the subject and environment, which is based on voluntary motor activity and on psychic and rational adaptation, always more oriented to developing abstract and individualised thinking.

Child development is manifested as the constant re-equilibration between the two processes and each time re-equilibration is achieved, a new stage of development is reached. Each development stage marks a gradual shift away from a type of intelligence based on actions carried out physically on material objects, and moves towards a type of intelligence based on abstract operations. Milestones are always based on mental operations, but concerning concrete reality, which can be perceived physically by the child (Berti, 2001).

The division of the development process into stages has a substantially descriptive value because it is a stable and continuous constant, with no interruptions and separations between the various moments, which instead are closely integrated to each other. In fact, the successful completion of each stage of development prepares the way for advancing to the next one.

Piaget's development stages differ from child to child because they are influenced by variables such as neurophysiological maturation, exercise and the social-cultural environment.

The first stage on sensorimotor intelligence characterises a child's thinking until the second year of life. He used this term because the child's activity during this period is characterised primarily by the use of sensory and motor skills, and intelligence consists of schemes of practical actions that gradually coordinate to give rise to broader behavioural sequences (Camaioni, 2007).

At first glance, it would seem that intelligence and motor activity are completely different activities. However, modern psychological studies show that there is continuity between the two and that the mental activity is simply a representation of the motor activity. Motor activity comes from a spontaneous manifestation, i.e. the body's reaction to the environment. It is organized around the basic needs, already from the time of birth (Trisciuzzi, 2001).

The sensorimotor stage in turn can be divided into different substages with specific characteristics:

1. Simple reflexes (0-1 month): the child is a bundle of reflexes, or fixed responses triggered by specific stimuli; for example, if we touch the lips of a newborn, it will suck reflexively. With the progressive development of the brain mass, these reflexes will gradually begin to change until they become voluntary actions. Over time, reactions to external signals will become more and more specific, therefore, babies will no longer be 
content to suck only to drink milk, but will suck anything given to them, making contact with the various aspects of their surrounding world. In this stage, the child reinforces, generalises and differentiates behaviour that begins in the form of reflexes. The child builds a world of things to suck, grab, watch, hit and listen to and at the end of this stage will perceive a human face and follow its movements with concentration.

2. Primary circular reactions (1-4 months): a circular reaction is a movement that is repeated several times. In a very random manner, the child discovers an interesting result due to its behaviour, and tries to keep it through repetition, which in turn creates a habit. These circular reactions are called "primary" reactions because they respond to results that are centred on or around the body of the child, rather than on other objects. A baby's occasional thumb-sucking action turns into systematic conduct thanks to the coordination between the schema of sucking and the movements of the hand. Primary circular reactions are also accompanied by a sense of pleasure.

3. Secondary circular reactions (4-8 months): these are not reflexes, but are still not true acts of intelligence because the new event is discovered by accident. The child accidentally does something that leads to an interesting result in the surrounding environment (for example, shakes a rattle that makes a noise). While in the previous stage the shaking or hitting was interesting in itself, the interest now comes from the consequences and reality acquires a certain permanence in the child, even if it is still connected to his actions.

4. The child grasps, looks for an object and finds it by observing the surrounding space. One of the most important acquisitions of this stage is the ability to coordinate the schemes of vision and prehension, which allows the child to grasp a desired object and bring it in front of his eyes.

5. Coordination of secondary schemes (8-12 months): this is the stage where the differentiation between means and ends occurs. To achieve a goal not immediately accessible, the child implements schemes he already possesses and applies them to a new situation.

6. Tertiary circular reactions (12-18 months): the child looks for new discoveries, his behaviour is no longer conservative; from the age of one, the environment becomes the child's laboratory, where they perform experiments to see what results can be achieved. The child takes full advantage of the objects, through attempts of trial and error, to discover new possibilities of the relationship between means and end. When a child finds an interesting result, he does not simply repeat it, but alters and changes it in order to study its nature.

7. Invention of new means through Mental Combinations (around 24 months): the sensorimotor period ends with this stage. The child no longer experiments through trial and error, but through invention. This stage marks the onset of a child's ability to think; he can now use mental symbols to represent objects and events. This mental representation leads to the emergence of new ways to solve problems.

Mental representation is formed by spontaneous motor activity, movement and organisation of "body and space". Piaget clearly showed that mental image derives directly from motor activity, starting from reflexive motor activity through to simple imitation and deferred motor imitation, which derives directly through the internalization of the motor schemes. If motor activity opens the way for the formation of the mental image, deferred imitation provides its contents, symbolic play gives it life and language its form. Language, in particular, influences the formation of the mental image because it gives a linguistic meaning to concrete reality. 
The biggest achievement in the second stage of development called the preoperatorial stage (from 2 to 6 years) is mental representation. The child is now able to use symbols, images, words and actions that represent something else. The child moves away from the pure material action on reality and starts to operate more at a mental level. The main manifestations of representative activity are deferred imitation, symbolic play and language.

In deferred representation, the child reproduces a model a few days later and this means that they have retained an internal model of the representation. Mental image is therefore the form through which reality (object, person, event) is represented mentally.

According to Piaget, "make-believe" play exists when children must apply their schemes of action to inappropriate objects, that is, different from the usual ones, or must give object qualities that are different from the actual ones. Even when using language to refer to objects, people or situations, the child shows that they know how to use certain patterns of thought.

These actions refer to a reality that is not present at that moment and are characterised by an intellectual egocentrism: therefore, the child does not think that reality can be presented to others in a different way from how they perceive it. In this stage, the actions are rigid and irreversible and thought can go beyond the current data because it reconstructs past actions and anticipates the consequences of actions not yet performed. However, due to irreversibility, each mental representation remains isolated.

In the next concrete operational stage (7-12 years) the child develops the type of thought that starts at school age. Thought, although still originating from action and direct experience, allows the child to unite and group together, in a global structure, representations and relations perceived individually.

The child does not only interact with the environment through their actions, but also through operations. Individual mental operations coordinate with each other to become concrete operations. They are conceived by Piaget as mental structures characterised by reversibility, so that a reverse action exists for each operation. Reversibility marks the genesis of logical thought because it allows the coordination of different points of view.

The final stage is known as formal operational stage (12 years onwards). In this stage, the child extends his reasoning capabilities to situations he does not know or has not personally experienced or that he cannot personally manipulate and examine. The child begins to think in terms of possible events and not so much of real events, and is capable of hypothetical and deductive reasoning.

Pre-teens see a reversal in the perspective of the knowledge of reality, where the latter is no longer represented by the source of their acts of knowledge, but is seen as one of the possible manifestations that allow a person to solve problems.

Whereas, a child's social-cultural development depends primarily on the historical and sociocultural context in which they live and on how they are placed in a condition to master the tools of culture. 
The studies by Vygotsky provide a fundamental contribution to the way of educating a child as a psychophysical and social unity, also made possible by the discovery of the concept of the zone of proximal development.

The zone of proximal development defines the distance between the actual level of development and the potential level of development, which allows evaluating what a child is able to do alone and what they are able to do with the help of more experienced people (adults or peers). The author believes that education should be based on the level of potential.

With the help of a more experienced adult or peer, a child could solve problems that he is not yet able to solve on his own, but that may soon become part of his individual skills.

This theory may be feasible and operational in schools and classes organised in a way that promotes and encourages the transition from what a student knows how to do to what they can do, encouraging the development of those functions that the child still cannot perform on their own or that are unknown to them.

Therefore, in this perspective, learning is seen as a tool for developing one's biological and physiological processes of maturation because it anticipates activation and evolution. It creates a zone of proximal development because it activates different evolutionary processes that are implemented only when the child interacts with his friends or other people who are part of his world (Paladino, 2002).

According to other scholars, the progress achieved through the zone of proximal development can be divided as follows:

Stage I: represents the stage when the performance is controlled by a more experienced person. Initially, the child will only understand part of the nature of the task or objective to be achieved, and is forced to rely on more experienced people to perform most of the work. The more experienced person initiates an action of demonstration and guidance, stimulating the child to complete the task.

Stage II: this is the stage in which the performance is controlled by the child. Over time, the child assumes much of the responsibility for a successful result that was previously given to the expert; therefore, he can act independently without the presence of an adult. The child will therefore be able to handle himself based on verbalisations expressed aloud.

Stage III: is the final stage, where the performance becomes automatic. The knowledge of carrying out the task is internalised, i.e. it is transferred from the social (or inter-mental) level to the psychological (or intra-mental) level.

What occurs in the zone of proximal development should not be limited to explicit educational forms of learning. It covers a wide range of other interactions that are quite casual and informal and that includes interplay or conversation, but nevertheless it has the same potential to increase knowledge in children (Schaffer, 2005).

For some time now neuroscientific studies have shown that experiences determine the mental and physical development of a person.

From a very young age, a child relates to the world through the figure of the mother, who helps them to understand the outside reality. Over time, the child gradually starts to establish contacts with other reference figures. 
Winnicott, an English paediatrician and psychoanalyst claims that, early in life, we all exist only as part of a relationship, and its ability to live and develop depends completely on the fulfilment of the basic need of attachment and belonging to someone (mother/caregiver) who looks after them and gives them a sense of security and intimacy that are fundamental to growth (Winnicott, 1970).

The healthy development of self depends on the emotional quality of this primary relationship, and on the availability, protectiveness, reliability, consistency and capacity of the attachment figure to provide warm and reassuring contact. The potential of a process through which the Self of a person is established begins when the mother sees the child for the first time and comes into contact with him (Kohut, 1976).

A child builds self-image from the dyadic relationship with his mother while inside the womb, and this relationship becomes reciprocal during the child's development.

The initial feelings registered by the foetus during the development of its nervous system are fusional feelings. The child lives in a state of total indifference, which in part is not separated from the mother's body ( Lapierre \& Aucouturier, 1991).

In the first months of life, the baby is a mosaic of feelings that arise from within its own body. This theory is defined in psychoanalysis as the fragmented body. Therefore, since the newborn is not able to have a global image of its body, it is not even able to perceive a global image of objects and other bodies. The face, hand, breasts of the mother or reference adult are partial objects not perceived globally, and are considered good or bad depending on the feelings of joy or sorrow they convey to the body. This is the stage of "partial object-love" identified by the scholar Melanie Klein.

According to Klein, the child's inner world is haunted by frightening and destructive objects and contains an Ego and an archaic Superego, resulting from the newborn's early object relationships with a partial object, such as the mother's breast, which is seen alternatively as a source of satisfaction when it is fulfilling and of frustration and persecution when it is not.

The whole harmonic image of the child is built around the image that the mother provides the child of herself. The emotional evolution of a person's entire future psychic and relational life depends on the first year of life. In fact, if free expression of the Self and of objects of affection encounter incomprehension, humiliation, disapproval or rejection, the child will quickly learn how to control its emotions by blocking the expressive muscles of emotion (Stern, 1987).

The reunification of the body ego appears at the age of eight to nine months thanks to the child's first motor and tactile experiences.

According to Winnicott, the child's self-image comes from the mother in the same way as a mirror, i.e. the mirror reflects the image of those who look into it. A child who can see, from a psychological point of view, his mother's face, sees an image of himself reflected in her eyes. This feedback or reflection is the core of the child's Self, on which his whole personality will develop and grow. 
This theoretical assumption is a basic step for psychic development, where the child initially has a unified image of his body, and then begins to separate his body and self from the world of objects and the world of others.

A mother who is able to enjoy the joys of breastfeeding and to communicate lovingly with her child while she takes care of him is creating the foundations for the development of the emotional mind, which in turn ensures the development of the child's cognitive mind. All this allows us to better understand how important and influential the relationship between mother and child is on the subsequent development of temperament and on the healthy development of body and mind. The English psychiatrist and psychoanalyst John Bowlby drew attention to the fundamental role of the mother-child relationship for the child's emotional organisation, his autonomy, social skills and physical and mental development.

Observations coming from various sources showed that the lack of maternal love in early childhood effects a child's mental health and personality (Bowlby, 2012).

Bowlby opposes the psychoanalytic theory, bringing the child's attachment to its mother back to an innate principle, which is based on the child's need to have close physical contact with that figure.

To refute the Freudian psychoanalytic theory of "interested love" according to which the child seeks the closeness of the mother to meet its basic needs in particular, to feed it, Bowlby gives the example of the experiment conducted by Harlow on rhesus monkeys. These studies show that the small monkeys reared with surrogate mothers - some made of wire with a full bottle of milk and others covered in soft cloth with no bottle - spent more time with the cloth mother, therefore the one that provides warmth and softness and not the one that feeds them.

Based on these observations, Bowlby theorised that the young child's attachment to its mother has essentially a protective function and promotes the survival of the young. The more the environment is perceived as a danger, the more the behaviour of attachment is manifested by the child.

Some types of attachment behaviour such as crying, clinging, and smiling are considered by Bowlby as pre-programmatic schemes, which develop because they encourage closeness and contact with the mother. This suggests that emotional and behavioural schemes of attachment, although pre-programmed, can be seen as responses produced when a real system of cybernetic control is activated in the individual: the system of attachment. This system is comparable to a control system that in some way indicates the dangerous nature of the situation. The danger can be made up of both a real external source and by a presumed absence of help from the caregiver. If the mother is absent or is not available, the child may experience separation anxiety, manifesting those behaviours that would be elicited in the face of real danger.

The behaviour centres on the "attachment structure", which is manifested in the first year of life. The most important types of behaviour in the child-mother relationship are smiling and crying, which communicate the needs of the child and consolidate the behaviour of the adult.

According to Bowlby, the bond of attachment develops through four stages that in some way are related to the stages of cognitive development: 
Stage I: pre-attachment ( 0 - 2 months) where the child's behaviour is characterised by reflexes and attachment behaviours, such as smiling, crying, clinging, but consist of signals that do not involve discrimination between different people, nor are they produced in an intentional way.

Stage II: attachment in the making (2-6/8 months) where the child produces signals and directs them to one or more people, usually the mother. Between 5 and 7 months, babies who are in a state of emotional distress receive comfort from the mother. In this stage, anxiety by separation from the reference figure (caregiver) still does not exist.

Stage III: clear-cut attachment (6/8 months - 2 years), in this period the child maintains a preferential contact with the mother/caregiver and the real attachment is structured. Attachment is manifested with anxiety from the seventh month where the child cries and protests on having to separate from the mother/caregiver. This stage coincides with Piaget's stage of "object permanence", when the child becomes aware of the absence of his mother and begins looking for her. In this period, the child also begins the activities of autonomous movement, and therefore starts to crawl and walk on all fours. Consequently, the child will try to follow and reach his mother in order to stay physically close to her, beginning his attempts at exploring the outside world.

Stage IV: formation of reciprocal relationship (from 18 months): in this stage a correct relationship is formed between the mother and child according to the purpose, i.e. a reciprocal relationship whose common goal is to give comfort and maintain closeness

\section{References}

Bertamini D., Iacchia E., Rinaldi S., Rezzonico G., Gioco, socialità e attaccamento nell'esperienza infantile, Franco Angeli, Milano 2009.

Berti A. E., Bombi A.S., Introduzione alla psicologia dello sviluppo, il Mulino, Bologna, 2001.

Bowlby J., Cure materne e salute mentale del bambino, Giunti, Firenze, 2012.

Camaioni L., Di Blasio P., Psicologia dello sviluppo, Bologna, il Mulino, Bologna, 2007.

Canestrari R., Godino A., Introduzione alla psicologia generale, Bruno Mondadori, Milano, 2002.

Cena L., Imbasciari A., Baldoni F., La relazione genitore-bambino. Dalla psicoanalisi infantile alle nuove prospettive evoluzionistiche dell'attaccamento, Springer, Milano 2010.

Fonzi A., Manuale di psicologia dello sviluppo. Storia, teorie e metodi. Lo sviluppo cognitivo, affettivo e sociale nel ciclo di vita, Giunti, Firenze 2001.

Gardner H., Educare al comprendere. Stereotipi infantili e apprendimento scolastico, Feltrinelli, Milano, 2002.

Gallo B., Neuroscienze e apprendimento, Ellissi, Napoli, 2003.

Kohut H., Narcisismo e analisi del Sé, Bollati Boringhieri, Torino, 1976.

Lapierre A., Aucouturier B., Il corpo e l'inconscio in educazione e terapia, Armando editore, Milan,1991.

Loriedo C., Picardi A., Dalla teoria generale dei sistemi alla teoria dell'attaccamento. Percorsi e modelli della psicoterapia sistemico-relazionale, Franco Angeli, Milano 2000.

Paladino A, Deficit in età scolare. Come intervenire, Pensa Multimediale, Lecce, 2002.

Peluffo N., La relazione psicobiologica madre-feto, EdizioniBorla, Roma 2010.

Peluffo N., La micropsicoanalisi, EdizioniBorla, Roma 1992.

Piaget J., La nascita dell'intelligenza del bambino, La Nuova Italia, Firenze, 1973.

Rosembaum D.A., Human Motor Control, Elsevier, USA 2010.

Schaffer H. R., Psicologia dello sviluppo. Un'introduzione, Raffaello Cortina Editore, Milano, 2005.

Stern D. N., Il mondo interpersonale del bambino, Bollati Boringhieri, Torino, 1987. 
Sgambelluri, R. (2016). The First Movements of the Child the Mental Structures and Dyadic Relatinship with the Mother. Advances in Social Sciences Research Journal, 3(12) 192-200.

Trisciuzzi L, Galantini M. A., Pedagogia e didattica speciale per insegnanti di sostegno e operatori della formazione, ETS, Pisa, 2001.

Winnicott D.W., Sviluppo affettivo e ambiente, Armando Editore, Roma, 1970. 